\title{
Editorial: Mycorrhizosphere Communication: Mycorrhizal Fungi and Endophytic Fungus-Plant Interactions
}

\author{
Erika Kothe ${ }^{1 *}$ and Katarzyna Turnau ${ }^{2}$ \\ ${ }^{1}$ Institute of Microbiology, Friedrich Schiller University, Jena, Germany, ${ }^{2}$ Institute of Environmental Sciences, Jagiellonian \\ University in Krakow, Kraków, Poland
}

Keywords: mycorrhiza, endophyte, fungus-plant interactions, mycorrhizophere, communication

Editorial on the Research Topic

Mycorrhizosphere Communication: Mycorrhizal Fungi and Endophytic Fungus-Plant Interactions

\section{PLANT MYCOBIOMES}

Plants do not exist as single entities but should rather be considered to form a complex community with microbes and other organisms where plant tissues form diverse niches for microbes. One major relationship concerns plant-fungal interactions that range from pathogenicity

OPEN ACCESS

Edited by:

Anna Maria Pirttilä,

University of Oulu, Finland

Reviewed by:

Tamás Papp

University of Szeged, Hungary

*Correspondence:

Erika Kothe

erika.kothe@uni-jena.de

Specialty section:

This article was submitted to Fungi and Their Interactions,

a section of the journal

Frontiers in Microbiology

Received: 12 September 2018 Accepted: 22 November 2018 Published: 05 December 2018

Citation:

Kothe E and Turnau K (2018) Editorial: Mycorrhizosphere Communication: Mycorrhizal Fungi and Endophytic

Fungus-Plant Interactions

Front. Microbiol. 9:3015.

doi: 10.3389/fmicb.2018.03015 to mutually beneficial symbioses. A balanced state (homeostasis) of these interactions is essential for maintaining the plant as well as an overall healthy state of the environment. Mycorrhizal associations are well-studied examples of root-fungal mutually beneficial symbiosis (Ferlian et al., 2018; Gehring and Johnson, 2018). The reasons for establishing a mutual symbiosis are only just beginning to be understood at the molecular level (Mello and Balestrini). Communication between endo- and ecto-mycorrhiza and their respective host plants (Raudaskoski and Kothe, 2015; Luginbuehl and Oldroyd, 2017; Garcia et al., 2018, and citations therein) and the effects on phytohormone levels and localized delivery (see Boivin et al., 2016; MacLean et al., 2017) have been the focus of several recent reports. But even so, a full understanding of these relationships will only be gained by investigating the effects of different strains of the same fungal species (Sharma et al.).

For roots, as well as above-ground plant tissues, endophytic fungi can be considered as examples of specific co-evolution, provided the term "endophytic" is used in its sensu strictu (for a detailed comment, see Kothe and Dudeja, 2011). To prove endophytic behavior, Koch's postulates need to be observed, and tissue specificity for re-infection may be used as a method to discriminate real endophytes from mere co-occurrence (Wȩżowicz et al., 2017; Domka et al., 2018; Ważny et al., 2018). The traits of endophytes that do not lead to symptoms in a healthy plant clearly delineate them from phytopathogenic fungi, however, caution is necessary because their effect on the symbiosis can vary with the species/variety of the partner and environmental conditions. For endophytic fungi, knowledge is much more limited as compared to mycorrhiza, although a role for strigolactone signaling is presented by Rozpądek et al.

Temporal shifts in plant-associated fungal populations are known to occur. An example from mycorrhizal symbiosis is for young trees with endomycorrhizal symbionts that are later replaced by specific ectomycorrhizal associations (Knoblochová et al., 2017; Bachelot et al., 2018). Within 4 weeks, vesicles and hyphae are visible in the roots of Picea abies and Pinus sylvestis leading to increased main-root development and up to a $300 \%$ increase in secondary roots. 
These effects alone will increase the potential at a later stage for formation of ectomycorrhiza, which is the only form of mycorrhiza seen in mature pine and spruce. After the ectomycorrhiza is established, a succession of fungal partners appears. First, fast-growing, broad host-range, reproductionstrategy fungi are attracted; later, slower growing, but more specific, ectomycorrhizal fungi, acting by capacity strategy, are recruited. For spruce, that would lead to replacement of, e.g., Cenococcum geophilum (see de Freitas Periera et al.) or Pisolithus tinctorius by host-specific fungi like T. vaccinum.

\section{MULTI-OMICS IN FUNGAL-PLANT MOLECULAR COMMUNICATION}

The mycobionts and their hosts will constantly communicate to establish and maintain the symbiosis. Signals are perceived and result in changes in gene expression. With excreted proteins or metabolites, the partner is stimulated. A multi-level interaction thus will be visible with changed transcriptome, proteome, and metabolome patterns. These can be visualized with techniques such as transcriptomics (Fiorilli et al., 2016; Nagabhyru et al., 2018), proteomics (Sebastiana et al., 2017; Shrivastava et al., 2018), metabolomics (Hill et al., 2018; Maciá-Vicente et al., 2018), or combinations thereof (e.g., Larsen et al., 2016). Since secreted proteins may be important for the signal exchange, secretomics can be expected to identify effector proteins exchanged between symbiont and host (Doré et al., 2015; Wagner et al., 2015). Volatiles exchanged address a subgroup of metabolites for signal exchange (Ditengou et al., 2015; Pistelli et al., 2017). And a combination of translatome and proteome data (Sharma et al.), as well as multi-omics have proven to substantially improve the quality of prediction for the symbiotic molecular network (Vijayakumar et al., 2016).

Interactions between symbiotic fungus and plant in production of secondary metabolites (Ludwig-Müller, 2015; González-Menéndez et al., 2016) shows the intricate relationship between the symbiotic partners. In addition to the dual interaction, the communication is expanded with additional fungi or bacteria which co-occur in the environment.

\section{MULTI-PARTNER INTERACTIONS}

Usually, plant and fungus are not alone in the partnership, but additional interactions with bacteria or other fungi will influence the outcome of these associations in nature. This complex relationship is reflected in the concept of the mycorrhizosphere, where plant roots and hyphae of the mycorrhizal partner encounter other soil microorganisms. These additional interactions in the vicinity of the root need to be considered in studies of cross-talk (Vannini et al., 2016; Wagner et al., 2016).

Phytohormones produced in the mycorrhizosphere may alter the physiology of the symbiotic partners and aid formation of new mycorrhiza (Wagner et al., 2015). For example, the ectomycorrhizal Tricholoma vaccinum produces the auxin indole-3-acetic acid (IAA), which stimulates mycorrhization (Krause et al., 2015). In addition, the exogenous presence of the phytohormone promotes branching, which leads to an increased Hartig-net formation during symbiosis (Krause et al., 2015). Moreover, ectomycorrhization can be reversed by associated fungi that produce IAA-inhibiting compounds (Hause and Saarschmidt, 2009). With soil zygomycetes, a tripartite interaction occurs in which the zygomycete-derived metabolite, D-orenone, induces a transporter that allows for increased excretion of IAA by the mycorrhizal fungus, $T$. vaccinum (Wagner et al., 2016). Soil bacteria are also capable of auxin biosynthesis, mostly upon tryptophan induction via root exudates. Since IAA increases branching of ectomycorrhizal fungi, some have been termed mycorrhiza-helper bacteria (Frey-Klett et al., 2016). It is now clear that multi-partner communication systems have evolved and are present in any habitat.

Like symbionts, phytopathogens also act via phytohormes, e.g., by inducing systemic-acquired resistance in host plants (Scholz et al.). Similar mechanisms of cross-talk can be inferred from comparison of pathosystems to endophytic or mycorrhizal symbiosis.

\section{MOLECULAR RESPONSES TO ENVIRONMENTAL STRESSES}

In addition to biotic interactions shaping the plant mycobiome, abiotic factors certainly influence the mutual, commensal or pathogenic interaction. Environmental conditions may influence plant mycobiomes, and these effects are more likely observed under detrimental conditions, such as nutrient limitation, drought, salinity, or other stresses, for example metal toxicity (Kumar and Verma, 2018; Shi et al., 2018). The molecular background of stress recognition and signal transduction within endomycorrhiza is reported by Sun et al. and an example of endophytes altering phosphate mobility in the mycorrhizosphere is given by Baum et al. The molecular background of stress recognition and signal transduction with an endomycorrhizal association is reported by Sun et al. as is an example of endophytes changing phosphate mobilities in the mycorrhizosphere (Baum et al.).

Environmental stresses, like metal contamination in the ground, to name just one example, can be buffered by mycorrhizal and endophytic associations. A molecular role has been shown for hydrophobins, small amphipatic proteins that decorate the cell wall of air-exposed mycelium. A study by Sammer et al. on the up-regulation of different hydrophobins during the life cycle of the mycorrhizal fungus exposed to metal contamination illustrates their protective effect. In that study, the biotic interaction is also characterized by volatiles and exudates from the host tree inducing mycorrhiza-associated hydrophobin genes (Sammer et al., 2016).

Transporter production, as well as intracellular storage of metals, illustrate specific adaptive responses in fungi. Many fungi are able to carry increased metal loads if grown on metalcontaminated substrate. A prominent example is the mushrooms 
that showed high cesium content when collected from the fallout areas after the Chernobyl accident. A molecular explanation is now available for this observation (see Benes et al.). For metals that are not only toxic, but essential for growth at lower concentrations, e.g., zinc, require the presence of a specific uptake and storage system. Indeed, for zinc, such a system has been described with the ectomycorrhizal fungus Suillus luteus (Coninx et al.). As an additional twist, there are fungi that influence mutual symbioses of bacteria with plants. An example of this is shown by Thiem et al. where the influence of microbiome, including the mycobiome, on the actinorrhizal interaction between Frankia and alder (Alnus glutinosa) under salinity is demonstrated.

\section{APPLICATIONS FOR GROWING DEMANDS ON SUSTAINABLE AGRICULTURE AND FORESTRY}

Anthropogenic impact, including industrial pollution and both conventional and organic agriculture, has already affected the soil microbiome, leading to decreases in soil quality and the nutritional value of crops. In doing so, it has created the necessity to use a range of chemicals, such as fertilizers and pesticides, to avoid the spread of unwanted pathogenic microbes. These substances not only affect plant-microbial foes but also the friendly microbes that help the plant to establish homeostasis and attain the nutritional quality of products that support the health of the consumers. The twenty first century brings us possibilities to develop new and innovative methods to rebuild soil tilth and to renovate the plant microbiota (see, e.g., Verzeaux et al., 2017; Campos et al., 2018). However, to be successful, we need an increased understanding by both food and wood producers

\section{REFERENCES}

Bachelot, B., Uriarte, M., Muscarella, R., Forero-Montaña, J., Thompson, J., McGuire, K., et al. (2018). Associations among arbuscular mycorrhizal fungi and seedlings are predicted to change with tree successional status. Ecology 99, 607-620. doi: 10.1002/ecy.2122

Boivin, S., Fonouni-Farde, C., and Frugier, F. (2016). How auxin and cytokinin phytohormones modulate root microbe interactions. Front. Plant Sci. 7:1240. doi: 10.3389/fpls.2016.01240

Campos, P., Borie, F., Cornejo, P., López-Ráez, J. A., López-García, Á., and Seguel, A. (2018). Phosphorus acquisition efficiency related to root traits: is mycorrhizal symbiosis a key factor to wheat and barley cropping? Front. Plant Sci. 9:752. doi: 10.3389/fpls.2018.00752

De Cuyper, C., and Goormachtig, S. (2017). Strigolactones in the Rhizosphere: friend or foe? Mol. Plant Microbe Interact. 30, 683-690. doi: 10.1094/MPMI-02-17-0051-CR

Dhawi, F., Datta, R., and Ramakrishna, W. (2017). Proteomics provides insights into biological pathways altered by plant growth promoting bacteria and arbuscular mycorrhiza in sorghum grown in marginal soil. Biochim. Biophys. Acta Proteins Proteom. 1865, 243-251. doi: 10.1016/j.bbapap.2016. 11.015

Ditengou, F. A., Müller, A., Rosenkranz, M., Felten, J., Lasok, H., van Doorn, M. M., et al. (2015). Volatile signalling by sesquiterpenes from ectomycorrhizal fungi reprogrammes root architecture. Nat. Commun. 6:6279. doi: $10.1038 /$ ncomms7279 on the molecular communication between fungi and the host plant, resulting in competitive advantages specifically under abiotic stress. The results may provide solutions for the problems aggravating sustainable agriculture and forestry, especially under the ever-changing environmental conditions (Shinde et al., 2018).

The re-introduction of protective microbes can be achieved through bioaugmentation strategies, which allow them to create optimal conditions for crop growth under harsh conditions (see Treu and Falandysz, 2017) and a reduction in the use of water, fertilizers, and pesticides. The most common plant inhabitants are endophytes that, when properly selected, can be a potent tool against pathogens and abiotic factors (see French, 2017). They also support mycorrhizae, which in turn contribute to plant growth and induce tolerance to salinity, pollution, drought, extreme temperatures, elevated $\mathrm{CO}_{2}$, etc. (see, e.g., Dhawi et al., 2017). The provision of well-selected microbes and the application of appropriate agricultural/forestry practices, both of which are feasible now, can decrease the current intensive use of fertilizers while maintaining an environment that is conducive to human health. Although nowadays the interaction of fungi and bacteria with plants is better understood, there is still a need for greater insight into the interplay between bacteria and fungi, fungi with other fungi, and their interactions with plants. Furthermore, building stronger bridges between bacteriologists and mycologists will help to benefit from their complementary skills, as exemplified by the work on the roles of strigolactones (see, De Cuyper and Goormachtig, 2017).

\section{AUTHOR CONTRIBUTIONS}

All authors listed have made a substantial, direct and intellectual contribution to the work, and approved it for publication.

Domka, A., Rozpądek, P., Ważny, R., and Turnau, K. (2018). Mucor sp. - an endophyte of Brassicaceae capable of surviving in toxic metal-rich sites. J. Basic Microbiol. doi: 10.1002/jobm.2018 00406. [Epub ahead of print].

Doré, J., Perraud, M., Dieryckx, C., Kohler, A., Morin, E., Henrissat, B., et al. (2015). Comparative genomics, proteomics and transcriptomics give new insight into the exoproteome of the basidiomycete Hebeloma cylindrosporum and its involvement in ectomycorrhizal symbiosis. New Phytol. 208, 1169-1187. doi: 10.1111/nph.13546

Ferlian, O., Biere, A., Bonfante, P., Buscot, F., Eisenhauer, N., Fernandez, I., et al. (2018). Growing research networks on mycorrhizae for mutual benefits. Trends Plant Sci. 23, 975-984. doi: 10.1016/j.tplants.2018.08.008

Fiorilli, V., Belmondo, S., Khouja, H. R., Abbà, S., Faccio, A., Daghino, S., et al. (2016). RiPEIP1, a gene from the arbuscular mycorrhizal fungus Rhizophagus irregularis, is preferentially expressed in planta and may be involved in root colonization. Mycorrhiza 26, 609-621. doi: 10.1007/s00572-0160697-0

French, K. E. (2017). Engineering mycorrhizal symbioses to alter plant metabolism and improve crop health. Front. Microbiol. 8:1403. doi: 10.3389/fmicb.2017.01403

Frey-Klett, P., Garbaye, J., and Tarkka, M. (2016). The mycorrhiza helper bacteria revisited. New Phytol. 176, 22-36. doi: 10.1111/j.1469-8137.2007.02191.x

Garcia, K., Delaux, P. M., Cope, K. R., and Ané J. M. (2018). Molecular signals required for the establishment and maintenance of ectomycorrhizal symbioses. New Phytol. 208, 79-87. doi: 10.1111/nph.13423 
Gehring, C. A., and Johnson, N. C. (2018). Beyond ICOM8: perspectives on advances in mycorrhizal research from 2015 to 2017. Mycorrhiza 28, 197-201. doi: 10.1007/s00572-017-0818-4

González-Menéndez, V., Pérez-Bonilla, M., Pérez-Victoria, I., Martín, J., Muñoz, F., Reyes, F., et al. (2016). Multicomponent analysis of the differential induction of secondary metabolite profiles in fungal endophytes. Molecules 21:234. doi: 10.3390/molecules21020234

Hause, B., and Saarschmidt, S. (2009). The role of jasmonates in mutualistic symbioses between plants and soil-borne microorganisms. Phytochemistry 70, 1589-1599. doi: 10.1016/j.phytochem.2009.07.003

Hill, E. M., Robinson, L. A., Abdul-Sada, A., Vanbergen, A. J., Hodge, A., and Hartley, S. E. (2018). Arbuscular mycorrhizal fungi and plant chemical defence: effects of colonisation on aboveground and belowground metabolomes. J. Chem. Ecol. 44, 198-208. doi: 10.1007/s10886-017-0921-1

Knoblochová, T., Kohout, P., Püschel, D., Doubková, P., Frouz, J., Cajthaml, T., et al. (2017). Asymmetric response of root-associated fungal communities of an arbuscular mycorrhizal grass and an ectomycorrhizal tree to their coexistence in primary succession. Mycorrhiza 27, 775-789. doi: 10.1007/s00572-017-0792-x

Kothe, E., and Dudeja, S. S. (2011). Editorial: plant-microbe interactions. J. Basic Microbiol. 51:4. doi: 10.1002/jobm.201190002

Krause, K., Henke, C., Asiimwe, T., Ulbricht, A., Klemmer, S., Schachtschabel, D., et al. (2015). Biosynthesis and secretion of indole-3-acetic acid and its morphological effects on Tricholoma vaccinum-spruce ectomycorrhiza. Appl. Environ. Microbiol 81, 7003-7011. doi: 10.1128/AEM.01991-15

Kumar, A., and Verma, J. P. (2018). Does plant-microbe interaction confer stress tolerance in plants: a review? Microbiol. Res. 207, 41-52. doi: 10.1016/j.micres.2017.11.004

Larsen, P. E., Sreedasyam, A., Trivedi, G., Desai, S., Dai, Y., Cseke, L. J., et al. (2016). Multi-omics approach identifies molecular mechanisms of plant-fungus mycorrhizal interaction. Front. Plant Sci. 6:1061. doi: 10.3389/fpls.2015.01061

Ludwig-Müller, J. (2015). Plants and endophytes: equal partners in secondary metabolite production? Biotechnol. Lett. 37, 1325-1334. doi: 10.1007/s10529-015-1814-4

Luginbuehl, L. H., and Oldroyd, G. E. D. (2017). Understanding the arbuscule at the heart of endomycorrhizal symbioses in plants. Curr. Biol. 27, R952-R963. doi: 10.1016/j.cub.2017.06.042

Maciá-Vicente, J. G., Shi, Y. N., Cheikh-Ali, Z., Grün, P., Glynou, K., Kia, S. H., et al. (2018). Metabolomics-based chemotaxonomy of root endophytic fungi for natural products discovery. Environ. Microbiol. 20, 1253-1270. doi: 10.1111/1462-2920.14072

MacLean, A. M., Bravo, A., and Harrison, M. J. (2017). Plant signaling and metabolic pathways enabling arbuscular mycorrhizal symbiosis. Plant Cell 29, 2319-2335. doi: 10.1105/tpc.17.00555

Nagabhyru, P., Dinkins, R. D., and Schardl, C. (2018). Transcriptomics of Epichloëgrass symbioses in host vegetative and reproductive stages. Mol. Plant Microbe Interact. doi: 10.1094/MPMI-10-17-0251-R. [Epub ahead of print].

Pistelli, L., Ulivieri, V., Giovanelli, S., Avio, L., Giovannetti, M., and Pistelli, L. (2017). Arbuscular mycorrhizal fungi alter the content and composition of secondary metabolites in Bituminaria bituminosa L. Plant Biol. 19, 926-933. doi: $10.1111 /$ plb. 12608

Raudaskoski, M., and Kothe, E. (2015). Novel findings on the role of signal exchange in arbuscular and ectomycorrhizal symbioses. Mycorrhiza 25, 243-252 doi: 10.1007/s00572-014-0607-2

Sammer, D., Krause, K., Gube, M., Wagner, K., and Kothe, E. (2016). Hydrophobins in the life cycle of the ectomycorrhizal basidiomycete Tricholoma vaccinum. PLOS ONE 11:e0167773. doi: 10.1371/journal.pone.0167773
Sebastiana, M., Martins, J., Figueiredo, A., Monteiro, F., Sardans, J., Peñuelas, J., et al. (2017). Oak protein profile alterations upon root colonization by an ectomycorrhizal fungus. Mycorrhiza 27, 109-128. doi: 10.1007/s00572-016-0734-z

Shi, W., Zhang, Y., Chen, S., Polle, A., Rennenberg, H., and Luo, Z. B. (2018). Physiological and molecular mechanisms of heavy metal accumulation in nonmycorrhizal versus mycorrhizal plants. Plant Cell Environ. doi: 10.1111/pce.13471. [Epub ahead of print].

Shinde, S., Naik, D., and Cumming, J. R. (2018). Carbon allocation and partitioning in Populus tremuloides are modulated by ectomycorrhizal fungi under phosphorus limitation. Tree Physiol. 38, 52-65. doi: 10.1093/treephys/tpx117

Shrivastava, N., Jiang, L., Li, P., Sharma, A. K., Luo, X., Wu, S., et al. (2018). Proteomic approach to understand the molecular physiology of symbiotic interaction between Piriformospora indica and Brassica napus. Sci. Rep. 8:5773. doi: 10.1038/s41598-018-23994-Z

Treu, R., and Falandysz, J. (2017). Mycoremediation of hydrocarbons with basidiomycetes-a review. J. Environ. Sci. Health B 52, 148-155. doi: 10.1080/03601234.2017.1261536

Vannini, C., Carpentieri, A., Salvioli, A., Novero, M., Marsoni, M., Testa, L., et al. (2016). An interdomain network: the endobacterium of a mycorrhizal fungus promotes antioxidative responses in both fungal and plant hosts. New Phytol. 211, 265-275. doi: 10.1111/nph.13895

Verzeaux, J., Hirel, B., Dubois, F., Lea, P. J., and Tétu, T. (2017). Agricultural practices to improve nitrogen use efficiency through the use of arbuscular mycorrhizae: basic and agronomic aspects. Plant Sci. 264, 48-56. doi: 10.1016/j.plantsci.2017.08.004

Vijayakumar, V., Liebisch, G., Buer, B., Xue, L., Gerlach, N., Blau, S., et al. (2016). Integrated multi-omics analysis supports role of lysophosphatidylcholine and related glycerophospholipids in the Lotus japonicus-Glomus intraradices mycorrhizal symbiosis. Plant Cell Environ. 39, 393-415. doi: 10.1111/pce. 12624

Wagner, K., Krause, K., David, A., Kai, M., Jung, E. M., Sammer, D. et al. (2016). Influence of zygomycete-derived D'orenone on IAA signalling in Tricholoma-spruce ectomycorrhiza. Environ. Microbiol. 18, 2470-2480. doi: 10.1111/1462-2920.13160

Wagner, K., Linde, J., Krause, K., Gube, M., Köstler, T., Sammer, D., et al. (2015). Tricholoma vaccinum host communication during ectomycorrhiza formation. FEMS Microbiol. Ecol. 91:fiv120. doi: 10.1093/femsec/fiv120

Ważny, R., Rozpądek, P., Jędrzejczyk, R. J., Śliwa, M., Stojakowska, A., Anielska, T., et al. (2018). Does co-inoculation of Lactuca serriola with endophytic and arbuscular mycorrhizal fungi improve plant growth in a polluted environment? Mycorrhiza 28, 235-246. doi: 10.1007/s00572-0180819-y

Wężowicz, K., Rozpądek, P., and Turnau, K. (2017). Interactions of arbuscular mycorrhizal and endophytic fungi improve seedling survival and growth in post-mining waste. Mycorrhiza 27, 499-511. doi: 10.1007/s00572-0170768-x

Conflict of Interest Statement: The authors declare that the research was conducted in the absence of any commercial or financial relationships that could be construed as a potential conflict of interest.

Copyright (c) 2018 Kothe and Turnau. This is an open-access article distributed under the terms of the Creative Commons Attribution License (CC BY). The use, distribution or reproduction in other forums is permitted, provided the original author(s) and the copyright owner(s) are credited and that the original publication in this journal is cited, in accordance with accepted academic practice. No use, distribution or reproduction is permitted which does not comply with these terms. 